\title{
Revista do

\section{INVERSÃO DO ÔNUS DA PROVA NO DIREITO AMBIENTAL: O QUE MUDOU APÓS A SÚMULA 618 DO STJ?}

\author{
Guilherme Back Koerich ${ }^{1}$
}

\begin{abstract}
RESUMO
O presente estudo visa analisar como a inversão do ônus da prova é aplicada no âmbito do direito ambiental, sobretudo após a recente edição da Súmula 618 do Superior Tribunal de Justiça. Corolário do princípio da precaução, a inversão do ônus da prova é mais um instrumento para garantir a máxima proteção ao meio ambiente. No entanto, algumas questões ainda não foram respondidas; e a forma de sua aplicação não é pacificada, a despeito da elaboração da referida súmula. Uma delas será tratada neste estudo: a inversão do ônus da prova nas questões envolvendo direito ambiental é automática ou depende do preenchimento dos requisitos tradicionais da hipossuficiência e verossimilhança? Para tanto, buscou-se investigar a origem do princípio da precaução e as lacunas deixadas pela Súmula 618 do STJ. Por fim, foi realizada uma sucinta análise da aplicação da inversão do ônus da prova em outros países.
\end{abstract}

Palavras-chave: Inversão do ônus da prova. Princípio da precaução. Direito ambiental.

\section{SPECIAL BURDEN OF PROOF IN ENVIRONEMTAL LAW: WHAT HAS CHANGED SINCE PRECEDENT N.618 OF STJ?}

\begin{abstract}
The present study aims at analyzing how the special burden of proof is applied in the environmental law, especially after the recent Precedent n. 618 of Superior Court of Justice. Corollary of the precautionary principle, the special burden of proof is yet another instrument to ensure maximum protection of the environment. However, some questions have not yet been answered and the form of their application is not pacified, despite the elaboration of the said Precedent. One of them will be dealt with in this study: is the shift of the burden of proof on issues involving environmental law automatic or does it depend on fulfilling the traditional requirements of hyposufficiency and verosimilitude? Thus, there will be discourses on the origin of the precautionary principle, as gaps left by the STJ's Precedent n. 618 and, finally, an analysis of the application of the shift of the burden of proof will be carried out in other countries.
\end{abstract}

Keywords: Shift of the burden of proof. Precautionary principle. Environmental law.

\footnotetext{
${ }^{1}$ Mestrando em Ciência Jurídica pela Universidade do Vale do Itajaí (UNIVALI), em regime de dupla titulação com a Delaware Law School. Especialista em Direito Administrativo pela Sociedade de Ensino Superior Estácio de Sá. Especialista em Direito Penal e Processo Penal pela Universidade do Vale do Itajaí (UNIVALI). E-mail: guilherme@koadvocacia.com.
} 


\section{INTRODUÇÃO}

O objetivo deste artigo é analisar as lacunas deixadas pela Súmula 618 do STJ, sobretudo quanto à compulsoriedade da aplicação da inversão do ônus da prova nas questões envolvendo o direito ambiental.

O artigo é dividido em três capítulos. O primeiro trata do princípio da precaução, que arrima a inversão do ônus da prova no direito ambiental, com um breve histórico, conceitos e suas fontes no direito brasileiro.

O segundo apresenta algumas lacunas da Súmula 618 do STJ, entre as quais a compulsoriedade da aplicação do ônus da prova no âmbito do direito ambiental, haja vista que os precedentes que fundamentaram o referido enunciado não deixam claro como o instituto deve ser aplicado.

No último capítulo, procura-se realizar uma comparação com outros países no que tange ao objeto do presente trabalho, mormente quanto à possibilidade e forma de aplicação da inversão do ônus da prova.

Por fim, nas considerações finais, apresentam-se os pontos conclusivos, seguido de estimulação para continuidade dos estudos e reflexões acerca da inversão do ônus da prova no âmbito do direito ambiental.

\section{PRINCÍPIO DA PRECAUÇÃO}

No acervo jurídico internacional, o princípio da precaução teve origem na década de 1980, estando explícita ou implicitamente mencionado em algumas cartas constitucionais (MINASSA, 2018, p.165).

Entretanto, outros autores (PINTO, 2005, p. 3) apontam o seu surgimento ainda na década de 70, como é o caso da Declaração de Estocolmo em 1972 (Declaração sobre meio ambiente) e a Carta de Direitos e Deveres Econômicos dos Estados - ONU n. 3281/74:

As políticas ambientais dos Estados devem promover e não afetar adversamente o atual e futuro potencial de desenvolvimento dos países em desenvolvimento. Todos têm a responsabilidade de velar para que as atividades realizadas dentro de sua jurisdição, ou sob seu controle, não causem danos ao meio ambiente de outros Estados ou zonas situadas fora dos limites da jurisdição nacional. (ORGANIZAÇÃO DAS NAÇÕES UNIDAS, 1974). 
Outros documentos também influenciaram o desenvolvimento do princípio da precaução no âmbito internacional, como a Declaração de Bergen (1990), Convenção de Helsinki (1992) e Tratado da União Europeia (1993) (CURRIE, 2005, p. 25).

No entanto, o documento que realmente disseminou a ideia internacionalmente foi o da Declaração do Rio sobre Meio Ambiente e Desenvolvimento, na Conferência das Nações Unidas sobre Meio Ambiente, realizada no Rio de Janeiro em 1992, momento importante para a consagração do princípio da precaução (DA SILVEIRA, 2003, p. 28).

Naquela ocasião, por meio da Declaração de Princípios do Rio, assim ficou estabelecido:

Com o fim de proteger o meio ambiente, o princípio da precaução deverá ser amplamente observado pelos Estados, de acordo com suas capacidades. Quando houver ameaça de danos graves ou irreversíveis, a ausência de certeza científica absoluta não será utilizada como razão para o adiamento de medidas economicamente viáveis para prevenir a degradação ambiental (ORGANIZAÇÃO DAS NAÇÕES UNIDAS, 1992).

É verdade que tais declarações não têm imperatividade jurídica, mas trazem importantes recomendações, servindo como fonte de direito internacional, uma vez que se tornam diretrizes a serem observadas pelos Estados no trato das questões pertinentes (DA SILVEIRA, 2003, p. 28).

O princípio da precaução é uma regra geral utilizada em situações em que haja ameaças sérias ou irreversíveis para a saúde ou meio ambiente, em que seja necessário agir para reduzir potenciais danos, levando em consideração os custos e benefícios dessa ação ou omissão (GILBERTSON, 2001, p. 129).

O referido instituto busca cautelas relacionadas a atividades e/ou comportamentos sobre os quais a ciência ainda não detenha uma gama razoável de informações a respeito das possíveis consequências nocivas daquela atividade (LEITE, 2007).

Acerca da temática em liça, sobreleva-se o magistério preciso de Paulo de Bessa Antunes (2006, p. 37), quando explica que “o princípio da precaução se materializa nas diversas normas que determinam a avaliação dos impactos ambientais dos diferentes empreendimentos capazes de causar lesão ao meio ambiente, ainda que potencialmente".

Compreendido o conceito e alcance do princípio da precaução, infere-se que, como consequência lógica, deve-se aplicar a inversão do ônus da prova nas demandas ambientais. Em outras palavras, nas causas envolvendo o direito ambiental, o fardo probatório 
recai àquele que praticar atividades capazes de causar danos ambientais (TROUWBORST, 2006, p. 220).

Isso porque frequentemente os demandantes não têm condições técnicas ou financeiras para embasar cientificamente sua demanda, motivo pelo qual o princípio da precaução é um mecanismo importante para inverter o ônus da prova (TERWINDT, 2008, p. 2).

\subsection{Inversão do Ônus da Prova no Direito Ambiental}

Conforme mencionado alhures, na Conferência das Nações Unidas sobre Meio Ambiente, realizada no Rio de Janeiro em 1992 (ECO 92), ficou estabelecido o princípio da precaução no âmbito nacional e, a partir daí, começou-se a aplicar a inversão do ônus probatório nas causas envolvendo proteção ao meio ambiente.

Ressalta-se que não há na legislação brasileira previsão específica acerca da inversão do fardo probatório nas causas ambientais. Ela é utilizada a partir do Código de Defesa do Consumidor (CDC), que, tal qual a Lei de Ação Civil Pública (LACP), dispõe sobre ações vinculadas aos interesses difusos(BARRA, 2002, p. 30).

$\mathrm{O}$ art. 6, VIII, do CDC reza que, entre outros, é direito básico do consumidor a inversão do ônus da prova, quando, a critério do juiz, for verossímil a alegação ou quando o consumidor for hipossuficiente. $\mathrm{O}$ art. 21 da LACP, por outro lado, estabelece que se aplica à defesa dos direitos e interesses difusos, coletivos e individuais o disposto no Título III do CDC.

Acerca dessa particularidade, vale ressaltar que, não obstante a inversão do ônus da prova estar prevista no Título I do CDC (Dos direitos do consumidor), trata-se de “disposição processual e, portanto, integra ontológica e teleologicamente o Título III" (BARRA, 2002, p. 34); por isso, justifica-se a aplicação do aludido instituto, por analogia, nas causas envolvendo direitos metaindividuais, a exemplo da proteção ao meio ambiente (DA SILVEIRA, 2003, p. 32).

Por não haver uma lei específica sobre o tema, o Superior Tribunal de Justiça, pautando-se tão somente em princípios, legislações análogas e seus próprios precedentes, editou a Súmula 618, a fim de encerrar as divergências acerca da aplicação da inversão do ônus da prova no âmbito do direito ambiental e pacificar seu posicionamento sobre a questão.

\section{SÚMULA 618 DO SUPERIOR TRIBUNAL DE JUSTIÇA}


No dia 24 de outubro de 2018, o Superior Tribunal de Justiça editou a Súmula 618, segundo a qual a inversão do ônus da prova aplica-se às ações de degradação ambiental (BRASIL, 2018).

As súmulas são enunciados que refletem o entendimento majoritário de um tribunal sobre um determinado tema, que seja objeto de reiteradas decisões no mesmo sentido. São, portanto, construções jurisprudenciais que visam o respeito à segurança jurídica, uma vez que, em tese, pacificam eventuais controvérsias.

No caso da Súmula 618 do STJ, contudo, ao menos uma dúvida subsiste: a inversão se aplica automaticamente ou se faz necessário analisar caso a caso, dependendo do preenchimento de alguns requisitos? Em outras palavras, a expressão "aplica-se" tem sentido de "deve ser aplicada" ou "pode ser aplicada"?

Quanto à inversão do ônus da prova nas relações consumeristas, sua aplicação não é compulsória, mas simples faculdade judicial que pode ou não ser concedida, a depender do preenchimento dos requisitos insculpidos no art. 6, inciso VIII, do CDC.

Humberto Theodoro Júnior (2017, p. 72) explica que a verossimilhança é o juízo de probabilidade, de veracidade da versão alegada pelo consumidor, e que a hipossuficiência é a impotência econômica ou de outra natureza, que demonstre uma dificuldade para o consumidor se desincumbir do ônus probandi.

Para a elaboração da Súmula 618 foram utilizados doze precedentes, dos quais sete $^{2}$ aplicam a inversão do ônus da prova de forma automática sob o argumento de que o princípio da precaução pressupõe essa inversão, transferindo para o suposto causador do dano o encargo de provar que sua conduta não ensejou riscos para o meio ambiente.

Os sete precedentes em comento se fundamentam basicamente em dois acórdãos paradigmáticos (REsp n. 1.060.753 e REsp n. 1.237.893), dos quais será feita uma breve análise.

Do corpo do aresto REsp n. 1.060.753, transcreve-se, por sua completude e precisão, o seguinte excerto:

\footnotetext{
${ }^{2}$ AgRg no AREsp 183202 SP, Rel. Ministro RICARDO VILLAS BÔAS CUEVA, TERCEIRA TURMA, julgado em 10/11/2015, DJe 13/11/2015); AgRg no AREsp 206748 SP, Rel. Ministro RICARDO VILLAS BÔAS CUEVA, TERCEIRA TURMA, julgado em 21/02/2013, DJe 27/02/2013; AgInt no AREsp 1090084 MG, Rel. Ministra ASSUSETE MAGALHÃES, SEGUNDA TURMA, julgado em 21/11/2017, DJe 28/11/2017; REsp 1060753 SP, Rel. Ministra ELIANA CALMON, SEGUNDA TURMA, julgado em 01/12/2009, DJe 14/12/2009; REsp 1237893 SP, Rel. Ministra ELIANA CALMON, SEGUNDA TURMA, julgado em 24/09/2013, DJe 01/10/2013; REsp 1330027 SP, Rel. Ministro RICARDO VILLAS BÔAS CUEVA, TERCEIRA TURMA, julgado em 06/11/2012, DJe 09/11/2012; e AgInt no AREsp 779250 SP, Rel. Ministro HERMAN BENJAMIN, SEGUNDA TURMA, julgado em 06/12/2016, DJe 19/12/2016. 
Desta feita, percebo que a análise sobre o ônus da prova, em ação por dano ambiental, deve ser dirimida pela interpretação das leis aplicáveis e à luz dos princípios norteadores do Direito Ambiental.

Isso porque, em regra, a inversão do ônus probatório deve assentar-se exclusivamente em disposição expressa de lei. Mas, no presente caso, essa inversão encontra fundamento também em princípios transversais ao ordenamento jurídico, quais sejam, os princípios ambientais.

[...]

No caso das ações civis por danos ambientais, entendo que o caráter público e coletivo do bem jurídico tutelado - e não a eventual hipossuficiência do autor da demanda em relação ao réu -, nos leva à conclusão de que alguns dos direitos do consumidor também devem ser estendidos ao autor daquelas ações, afinal essas buscam resguardar (e muitas vezes reparar!) o patrimônio público de uso coletivo, consubstanciado no meio ambiente.

A essas normas agrega-se o Princípio da Precaução. Esse preceitua que o meio ambiente deve ter em seu favor o benefício da dúvida no caso de incerteza (por falta de provas cientificamente relevantes) sobre o nexo causal entre determinada atividade e um efeito ambiental negativo (BRASIL, 2009b).

Nesse diapasão, colhe-se do REsp n. 1.237.893, também de relatoria da Ministra Eliana Calmon, o seguinte:

\footnotetext{
Ademais, em se tratando de ação ambiental, impõe-se a inversão do ônus da prova, cabendo ao empreendedor, no caso o próprio Estado, responder pelo potencial perigo que causa ao meio ambiente, em respeito ao princípio da precaução.

$[\ldots]$

O princípio da precaução pressupõe a inversão do ônus probatório, competindo a quem supostamente promoveu o dano ambiental comprovar que não o causou ou que a substância lançada ao meio ambiente não lhe é potencialmente lesiva. (BRASIL, 2013).
}

Percebe-se, pois, que os sete precedentes (todos fundamentados no REsp n. 1.237.893 e/ou Resp n. 1.060.753) sustentam a inversão do ônus da prova no direito ambiental de forma compulsória e automática, visto que o princípio da precaução pressupõe a utilização do aludido instituto.

Por outro lado, outras quatro decisões fundamentam ${ }^{3}$ o cabimento da inversão do ônus da prova, se respeitadas as Leis n. 8.078/90 e n. 7.347/85. É importante ressaltar o

\footnotetext{
${ }^{3} \mathrm{AgRg}$ no AREsp 533786 RJ, Rel. Ministro ANTONIO CARLOS FERREIRA, QUARTA TURMA, julgado em 22/09/2015, DJe 29/09/2015; AgInt no AREsp 846996 RO, Rel. Ministro RAUL ARAÚJO, QUARTA TURMA, julgado em 04/10/2016, DJe 19/10/2016; REsp 1049822 RS, Rel. Ministro FRANCISCO FALCÃO, PRIMEIRA TURMA, julgado em 23/04/2009, DJe 18/05/2009; e, REsp 1517403 AL, Rel. Ministro HERMAN BENJAMIN, SEGUNDA TURMA, julgado em 25/08/2015, DJe 16/11/2015.

Rev. do Cejur: Prestação Jurisdicional, Florianópolis v.7 n.1, p. 238-251, Janeiro-Dezembro. 2019 
cuidado dos julgados quando dizem "ser cabível” (e não de forma automática e compulsória) a inversão do ônus da prova.

O AREsp n. 533.786, de relatoria do Ministro Antonio Carlos Ferreira, utilizado como paradigma também no AREsp n. 846.996, utiliza alguns outros julgados para fundamentar seu posicionamento pelo cabimento da inversão do ônus probatório, como por exemplo, o AREsp n. 15.3797, cuja ementa é:

[...] Inversão do ônus da prova no âmbito de ação de indenização por dano ambiental. Acórdão estadual que, corroborando a decisão saneadora, considerou cabida a inversão do ônus probatório, ante a constatação da verossimilhança do direito alegado (tendo em vista a responsabilidade objetiva decorrente do risco da atividade econômica empreendida e a notoriedade do acidente ambiental), bem assim a hipossuficiência técnica e financeira da vítima/autor. Incidência da súmula 7/STJ. (BRASIL, 2014).

Nesse mesmo sentido, o REsp n. 1.049.822, que fundamenta também o REsp n. 1.517.403, tem a seguinte ementa:

AÇÃO CIVIL PÚBLICA. DANO AMBIENTAL. AGRAVO DE INSTRUMENTO. PROVA PERICIAL. INVERSÃO DO ÔNUS. ADIANTAMENTO PELO DEMANDADO. DESCABIMENTO. PRECEDENTES. I - Em autos de ação civil pública ajuizada pelo Ministério Público Estadual visando apurar dano ambiental, foram deferidos a perícia e o pedido de inversão do ônus e das custas respectivas, tendo a parte interposto agravo de instrumento contra tal decisão. II - Aquele que cria ou assume o risco de danos ambientais tem o dever de reparar os danos causados e, em tal contexto, transfere-se a ele todo o encargo de provar que sua conduta não foi lesiva. III - Cabível, na hipótese, a inversão do ônus da prova que, em verdade, se dá em prol da sociedade, que detém o direito de ver reparada ou compensada a eventual prática lesiva ao meio ambiente artigo $6^{\circ}$, VIII, do CDC c/c o artigo 18 da lei ${ }^{\circ} 7.347 / 85$. IV - Recurso improvido. (BRASIL, 2009a).

Resta cristalino, portanto, que esses quatro julgados acolhem a possibilidade de inversão do ônus da prova, mas a fundamentam com o Código de Defesa do Consumidor, que, por sua vez, exige o preenchimento de requisitos (hipossuficiência e verossimilhança) para emprego dessa inversão. Não há, assim, uma aplicação compulsória e automática, mas uma possibilidade de utilização do instituto se respeitadas aquelas legislações.

Ainda em análise dos prejulgados que arrimam a Súmula n. 618, insta mencionar o REsp n. 883656, com o brilhante voto do Ministro Herman Banjamin, que discorre sobre a possibilidade da inversão do ônus da prova no direito ambiental, considerando a distribuição dinâmica do ônus da prova. 
No campo do Direito Ambiental, aplicáveis com maior razão os fundamentos teórico-dogmáticos do ônus dinâmico, acima aludidos. Mas não é só. A própria natureza indisponível do bem jurídico protegido (o meio ambiente), de projeção intergeracional, certamente favorece uma atuação mais incisiva e proativa do juiz, que seja para salvaguardar os interesses dos incontáveis sujeitos-ausentes, por vezes toda a humanidade e as gerações futuras. Ademais, o cunho processual do art. $6^{\circ}$, VIII, do CDC liberta essa regra da vinculação exclusiva ou confinamento à relação jurídica de consumo. Por derradeiro, a incidência do princípio da precaução, ele próprio transmissor por excelência de inversão probatória, base do princípio in dubio pro natura, induz igual resultado na dinâmica da prova, aliás como expressamente reconhecido pelo STJ, conforme precedentes adiante transcritos". (BRASIL, 2010).

Assim, infere-se do julgado, salvo melhor juízo, que a inversão do ônus da prova é recomendada e possível, mas também não se deixa claro se deverá ou não ser aplicada compulsoriamente. $\mathrm{Na}$ verdade, a distribuição do ônus da prova significa, como bem salienta o Ministro Herman Benjamin, que "o encargo de provar deve ser suportado por quem melhor e mais facilmente possa fazê-lo, conforme circunstâncias da demanda" (BRASIL, 2010). Ou seja, trata-se de um juízo de valor, de uma análise caso a caso, pois, mesmo que por uma remota possibilidade jurídica, o demandante pode ter maiores conhecimentos e técnicas do que o agente que supostamente comete o dano ambiental.

Percebe-se, assim, que os precedentes que arrimam a súmula são uníssonos quanto à possibilidade de inversão do ônus da prova nas questões ambientais, mas não quanto à sua aplicação de forma automática, devendo-se, em alguns casos, analisar a hipossuficiência do demandante.

Dessa forma, se a súmula tem como objetivo a preservação da segurança jurídica, no caso em comento houve um enorme fracasso. Conforme supramencionado, o enunciado, de per si, não esclarece se a inversão do ônus probatórios nas causas envolvendo direito ambiental é compulsória e automática, ou se se é apenas possível sua aplicação, se preenchidos os requisitos de hipossuficiência e verossimilhança.

Não bastasse isso, verificou-se que doze precedentes fundamentaram a aludida súmula, e em sete deles há indicação de que a inversão deve ocorrer de forma automática, pelo simples fato de se tratar de uma matéria envolvendo danos ao meio ambiente. Por outro lado, outros quatro precedentes tendem a considerar o preenchimento dos requisitos estabelecidos no art. 6, VIII, do CDC, bem como aqueles que fundamentam a distribuição dinâmica da prova. 


\section{A INVERSÃO DO ÔNUS DA PROVA NO EXTERIOR}

Esses questionamentos não são diferentes no âmbito internacional. Monika Ambrus (2012, p. 259) ressalta que ainda há incertezas e ambiguidades no conceito e aplicação do princípio da precaução nas leis ambientais internacionais; e isso tem ligação direta com a inversão do ônus da prova.

No entanto, quando se fala em direito ambiental, ao menos no âmbito interestadual, uma das interpretações existentes é no sentido de que o princípio da precaução implica a inversão do ônus da prova (AMBRUS, 2012, p. 259).

Esse assunto foi tratado na European Commission (2000), que adotou o princípio da precaução. O escopo foi informar às partes interessadas como a Comissão pretendia aplicar o aludido princípio e estabelecer diretrizes para isso.

A Comissão analisou duas situações: a primeira, em que uma empresa tenha intenção de introduzir um novo produto no mercado, e a segunda, em que uma organização não governamental questione os riscos de um produto já existente no mercado. $\mathrm{O}$ resultado disso, no que tange à inversão do ônus da prova, é que, no primeiro caso, considerando o princípio da precaução, a empresa é obrigada a mostrar que não há (sérios) riscos à saúde e ao meio ambiente. Já no segundo exemplo, a Comissão entendeu que a regra geral para aplicação do ônus da prova deveria ser mantida (AMBRUS, 2012, p. 269).

Nesse último caso, portanto, a parte que alega tem o dever de prover evidências de riscos existentes, o que pode se comparar, no direito brasileiro, à verossimilhança a que alude o Código de Defesa do Consumidor. Assim, por imposição do princípio da precaução, a inversão do ônus da prova não se daria de forma automática.

Outros países também vêm aceitando e aplicando o princípio da precaução e a inversão do ônus da prova. Exemplo disso é a Suprema Corte da Índia, que adotou o referido princípio como parte da lei ambiental no país. Em um dos casos analisados na Corte (Vellore Citizens Welfare Forum v. Union of India), o juiz Kuldip Singh explicou que o ônus da prova é do criador do suposto dano (empresário, construtor, etc.), que deve demonstrar que seus atos são benignos ao meio ambiente (VERMA, 2016, p. 281).

Nos Estados Unidos, de igual modo, a correta aplicação do ônus probatório é considerada um dos principais mecanismos legais de aplicação do princípio da precaução (KANNAN, 2007, p. 430).

Foi assim que decidiu a Corte de Apelação de Michigan no caso Township of Grosse Ile v. Dunbar \& Sullivan Dredging Co., que envolvia a tentativa de construção de 
pequenos abrigos na costa de uma ilha. O tribunal, em primeira instância, entendeu que as águas têm um valor público substancial e proibiu a referida construção, pois ela traria danos e enfraqueceria esse valor. $\mathrm{O}$ demandado apelou, sustentando que os autores não conseguiram provar o valor substancial ou enfraquecimento da confiança pública naquele caso (OLSON, 1990, p. 892).

No entanto, a Corte de Apelação manteve a decisão, indicando que o ônus de provar caberia à empresa ré, portanto invertendo o ônus da prova em face do interesse público nesse caso ambiental.

Em análise dessa decisão, James Olson afirma que a inversão do ônus da prova àqueles que alteram o status quo obriga-os a ponderar os custos e benefícios de suas condutas. Inclusive, com base na Federal Resource Conservation and Recovery Act (RCRA) - Lei de Conservação e Recuperação de Recursos -, a responsabilidade é imposta ao réu se ficar demonstrado que suas condutas apresentam um iminente e substancial perigo ao meio ambiente (OLSON, 1990, p. 892).

Em outro caso (Michie v. Great Lakes Steel), a Corte americana afirmou que a jurisprudência é pacífica quanto à impossibilidade de colocar sobre a parte lesada (o autor) o fardo de provar os danos causados pelo réu (UNITED STATES COURT OF APPEALS, 1974).

Desse modo, infere-se dos precedentes americanos que a inversão do ônus da prova é aplicável em diversos casos envolvendo danos ao meio ambiente. No entanto, é possível perceber que a inversão do ônus da prova não ocorre necessariamente de forma automática, mas, por vezes, preenchendo requisitos.

Sendo essa questão controvertida no Brasil e no âmbito internacional, para que haja completa proteção aos interesses difusos, sobretudo por uma questão de segurança jurídica, faz-se necessária a elaboração de um enunciado normativo a respeito do tema, de modo a sanar dúvidas quanto à compulsoriedade da inversão do fardo probatório e a fim de fornecer ao meio ambiente máxima proteção, em respeito aos tratados e convenções internacionais nesse sentido.

\section{CONCLUSÃO}

Fosse o objetivo da Súmula 618 encerrar a discussão acerca da compulsoriedade da inversão do ônus da prova nas questões envolvendo direito ambientou, ela falhou. 
Conforme mencionado alhures, a expressão "aplica-se" no enunciado do STJ não deixa claro se a inversão será sempre aplicada (de forma automática, portanto, pelo simples fato de tratar de matéria ambiental e consequente direito difuso) ou se o instituto é possível desde que preenchidos os requisitos para tanto.

Se for essa última opção, a súmula não precisaria existir, pois, conforme discorrido anteriormente, o Código de Defesa do Consumidor consubstanciado com a Lei de Ações Civis Públicas, além da jurisprudência dominante, já arrimava a referida inversão.

Por outro lado, se a intenção era tornar a inversão algo automático, por força do princípio da precaução e indubio pro natura, a súmula não foi incisiva, dando azo a dúvidas.

Essas dúvidas são potencializadas, principalmente, ao se analisar os precedentes que arrimaram a Súmula 618, tendo em vista que sete deles aplicam a inversão do modo automático (pela decorrência lógica do princípio da precaução), enquanto os cinco outros se manifestam pelo cabimento da inversão do ônus da prova sob a condição de se comprovar a hipossuficiência do autor e a verossimilhança das alegações, conforme preconiza o Código de Defesa do Consumidor, ou utilizando-se a distribuição dinâmica da prova.

No âmbito internacional, de igual modo, as cortes há muito aplicam o princípio da precaução e a "utilização especial" do ônus da prova, mas também não há consenso quanto à compulsoriedade de sua aplicação.

O Brasil é um país juridicamente evoluído quando se trata de proteção ao meio ambiente - inclusive apresentou na Conferência das Nações Unidas sobre Meio Ambiente (ECO92) a necessidade de se respeitar o princípio da precaução. A partir daí, tamanha a influência do país no âmbito internacional, diversos outras nações adotaram o referido princípio como viga mestra nas causas envolvendo direito ambiental.

Talvez por essa importância no cenário internacional, a Súmula 618 do STJ frustra ao silenciar, num momento tão oportuno, acerca da obrigatoriedade de aplicação da inversão do ônus da prova nas causas envolvendo proteção ao meio ambiente.

Sendo um país signatário de diversos tratados e convenções sobre o meio ambiente, espera-se do Brasil um posicionamento efetivo sobre o tema, inclusive em conjunto com outras nações, uma vez que há muito já se sabe que o meio ambiente não tem fronteira: trata-se de um interesse mundial.

\section{REFERÊNCIAS}


AMBRUS, Monika. The precautionary principle and a fair allocation of the burden of proof in international environmental law. Review of European Community \& International Environmental Law, 2012.

ANTUNES, Paulo de Bessa. Direito Ambiental. 9. edição revista, ampliada e atualizada. Lumen Juris Editora, 2006.

BARRA, Leandro Moreira. A inversão do ônus da prova na perícia ambiental. Fórum de Direito Urbano e Ambiental. Belo Horizonte: Fórum, 2002.

BRASIL. Superior Tribunal de Justiça. Recurso Especial n. 1.049.822. Relator Ministro Francisco Falcão. j. 23 de abril de 2009. 2009a. Disponível em: < https://ww2.stj.jus.br/processo/revista/documento/mediado/?componente=ATC\&sequencial= $3913453 \&$ num_registro $=200800840619 \&$ data $=20090518 \&$ tipo $=51 \&$ formato $=P D F>$. Acesso em: 29 mar. 2019.

BRASIL. Superior Tribunal de Justiça. Recurso Especial n. 1.060.753. Relatora Ministra Eliana Calmon. j. 01 de dezembro de 2009. 2009b. Disponível em: $<$ https://ww2.stj.jus.br/processo/revista/documento/mediado/?componente=ATC\&sequencial $=6767918 \&$ num_registro $=200801130826 \&$ data $=20091214 \&$ tipo $=51 \&$ formato $=P D F>$.

Acesso em: 29 mar. 2019.

BRASIL. Superior Tribunal de Justiça. Recurso Especial n. 1.237.893. Relatora Ministra Eliana Calmon. j. 24 de setembro de 2013. Disponível em: < https://ww2.stj.jus.br/processo/revista/documento/mediado/?componente=ATC\&sequencial= $31144739 \&$ num_registro $=201100265904 \&$ data $=20131001 \&$ tipo $=51 \&$ formato $=P D F>$.

Acesso em: 29 mar. 2019.

BRASIL. Superior Tribunal de Justiça. Recurso Especial n. 883.656. Relator Ministro Herman Benjamin. j. 09 de março de 2010. Disponível em: < https://ww2.stj.jus.br/processo/revista/documento/mediado/?componente=ATC\&sequencial= $8253735 \&$ num_registro $=200601451399 \&$ data $=20120228 \&$ tipo $=51 \&$ formato $=P D F>$. Acesso em: 29 mar. 2019.

BRASIL. Superior Tribunal de Justiça. Súmula 618. In: Súmulas Anotadas. Brasília: DJe, $2018 . \quad$ Disponível em: http://www.stj.jus.br/SCON/sumanot/toc.jsp?materia=\%27DIREITO\%20AMBIENTAL\%27. mat.\#TIT2TEMA0> Acesso em 12 de jun. de 2019.

CURRIE, Sarah. Applying the precautionary principle - na overview. Sniffer, maio 2005. Disponível em: <https://lwecext.rl.ac.uk/PDF/SNIFFER_UKCC05.pdf>. Acesso em: 28 mar. 2019.

DA SILVEIRA, Clóvis Eduardo Malinverni. A inversão do ônus da prova na reparação do dano ambiental difuso. In: LEITE, José Rubens Morato; DANTAS, Marcelo Buzaglo (Coord.). Aspectos processuais do direito ambiental. Rio de Janeiro: Forense Universitária, 2003. 
EUROPEAN COMISSION. Comission adopts communication on precautionary principle. Brussels, 2000. Disponível em: <http://europa.eu/rapid/press-release_IP-0096_en.htm>. Acesso em: 8 mar. 2019.

GILBERTSON, Michael. Late lessons from early warnings: the precautionary principle 1896-2000. European Environment Agency, 2001. Disponível em: <https://www.eea.europa.eu/publications/environmental_issue_report_2001_22/Issue_Report _No_22.pdf/view>. Acesso em: 27 mar. 2019.

KANNAN, Phillip. The precautionary principle: more than a cameo appearance in United States environmental law? Wm. \& Mary Envtl. L. \& Pol'y /Ver, 2007. Disponível em: $<$ https://scholarship.law.wm.edu/cgi/viewcontent.cgi?article=1083\&context=wmelpr $>$.

Acesso em: 27 mar. 2019.

LEITE, José Rubens Morato; FAGÚNDEZ, Paulo Roney Ávila. Biossegurança e novas tecnologias na sociedade de risco: aspectos jurídicos, técnicos e sociais. Florianópolis: Conceito Editorial, 2007.

MINASSA, Pedro Sampaio. A incógnita ambiental do princípio da precaução. Revista Direito Ambiental e Sociedade, v. 8, n.1, 2018.

OLSON, James M. Shifting the burden of proof: how the common law can safeguard nature and promote an earth ethic. Environmental Law, vol. 20, n. 4, 1990, pp. 891-915. Disponível em: <https://www.jstor.org/stable/43265949>. Acesso em: 21 mar. 2019.

ORGANIZAÇÃO DAS NAÇÕES UNIDAS. Carta de direitos e deveres econômicos dos estados - Res. n. 3281/74. ONU: 1974.

Disponível

Declaração do Rio sobre meio ambiente e desenvolvimento. ONU: 1992. <http://www.meioambiente.pr.gov.br/arquivos/File/agenda21/Declaracao_Rio_Meio_Ambien te_Desenvolvimento.pdf>. Acesso em: 28 mar. 2019.

PINTO, Oriana Piske de Azevedo Magalhães. Clonagem e transgênicos ante os princípios da dignidade da pessoa humana e da precaução no direito ambiental. Boletim Científico Escola Superior do Ministério Público da União, a.4 - n-14, jan./mar. 2005. Disponível em: $<$ https://www.tjdft.jus.br/institucional/imprensa/artigos/2006/clonagem-e-transgenico-anteos-principios-da-dignidade-da-pessoa-humana-e-da-precaucao-no-direito-ambiental-juizaoriana-piske> Acesso em: 27 mar. 2019.

TERWINDT, Carolijn. The burden of proof: evidence in environmental litigation. Evidence \& Influence. 2008. Disponível em: <https://micromag.evidenceandinfluence.org/article/theburden-of-proof-evidence-in-environmental-litigation/index.html>. Acesso em: 08 mar. 2019.

THEODORO JÚNIOR. Humberto. Direitos do consumidor. 9. ed. ref. e atual. Rio de Janeiro: Forense, 2017.

TROUWBORST, Arie. Precautionary rights and duties of states, tekst: Proefschrif Universiteit Utrecht, 2006. 
UNITED STATES COURT OF APPEALS. Michie v. Great Lakes Steel Div., Nat'l Steel. 495 F.2d 213. 6th Cir: 1974. Disponível em: < https://casetext.com/case/michie-v-great-lakessteel-div-natl-steel>. Acesso em: 21 mar. 2019.

VERMA, Rajinder. Management of natural resources and laws in India. Laxmi Book Publication, 2016. 